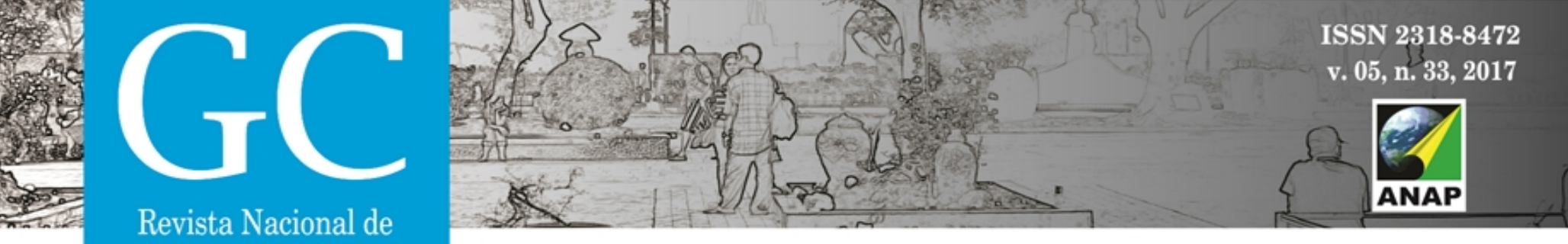

Revista Nacional de

Gerenciamento de Cidades

National Journal of Citiex Manasemen

\title{
Zoneamento para o Ambiente Cultural do município de Magé/RJ
}

Creating a cultural environment limit for Magé/RJ

Zonificación para el Ambiente Cultural del municipio de Magé/RJ

Silvia Scoralich de Carvalho

Discente, Mestrado Profissional em Projeto e Patrimônio do PROARQ/UFRJ

sscoralich@gmail.com 


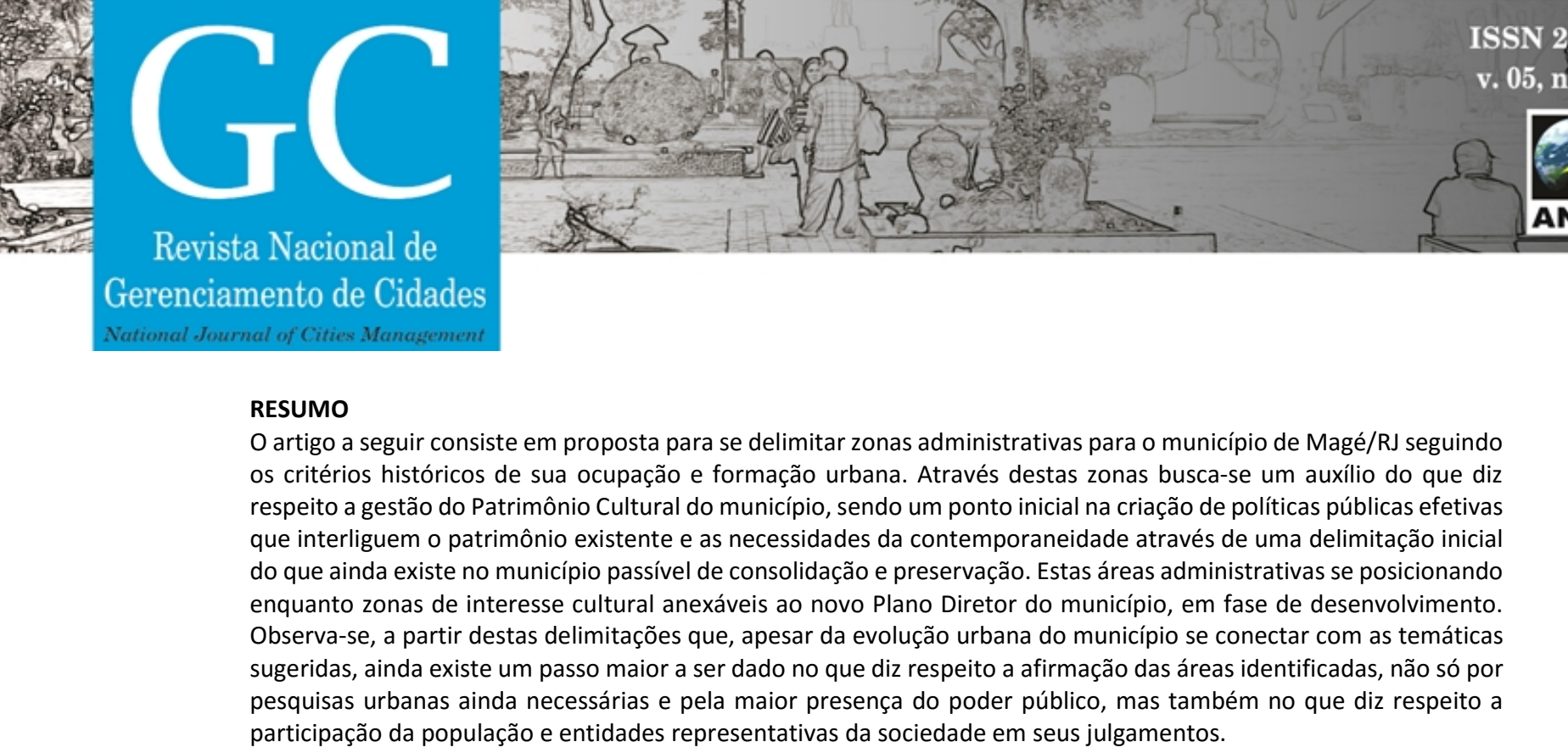

PALAVRAS-CHAVE: Zoneamento, Patrimônio Cultural, Magé.

\section{SUMMARY}

The following article consists of a proposal to delineate administrative zones for the city of Magé/RJ, following the historical criteria of their occupation and urban formation. Through these zones, an aid is sought regarding the management of the Cultural Patrimony of the municipality, being an initial point in the creation of effective public policies that interconnect the existing patrimony and the necessities of contemporaneity through an initial delimitation of what still exists in the municipality that can be consolidated and preserved. These administrative areas are positioned as areas of cultural interest appended to the new Master Plan of the municipality, in development phase. It is observed from these delimitations that, although the urban evolution of the municipality is connected with the themes suggested, there is still a greater step to be taken regarding the affirmation of the identified areas, not only by urban research still necessary and more presence of public power, but also regarding the participation of the population and representative entities of society in their judgments.

KEY WORDS: Zoning, Cultural heritage, Magé.

\section{RESUMEN}

El artículo siguiente consiste en propuesta para delimitar zonas administrativas para el municipio de Magé / RJ siguiendo los criterios históricos de su ocupación y formación urbana. A través de estas zonas se busca una ayuda de la gestión del Patrimonio Cultural del municipio, siendo un punto inicial en la creación de políticas públicas efectivas que interliguen el patrimonio existente y las necesidades de la contemporaneidad a través de una delimitación inicial de lo que todavía existe en el marco el municipio pasible de consolidación y preservación. Estas áreas administrativas se posicionan como zonas de interés cultural anexibles al nuevo Plan Director del municipio, en fase de desarrollo. Se observa, a partir de estas delimitaciones que, a pesar de que la evolución urbana del municipio se conecta con las temáticas sugeridas, todavía existe un paso mayor a ser dado en lo que se refiere a la afirmación de las áreas identificadas, no sólo por investigaciones urbanas aún necesarias y por la mayor presencia del poder público, pero también en lo que se refiere a la participación de la población y entidades representativas de la sociedad en sus juicios

PALABRAS CLAVE: Zonificación, patrimonio cultural, Magé. 


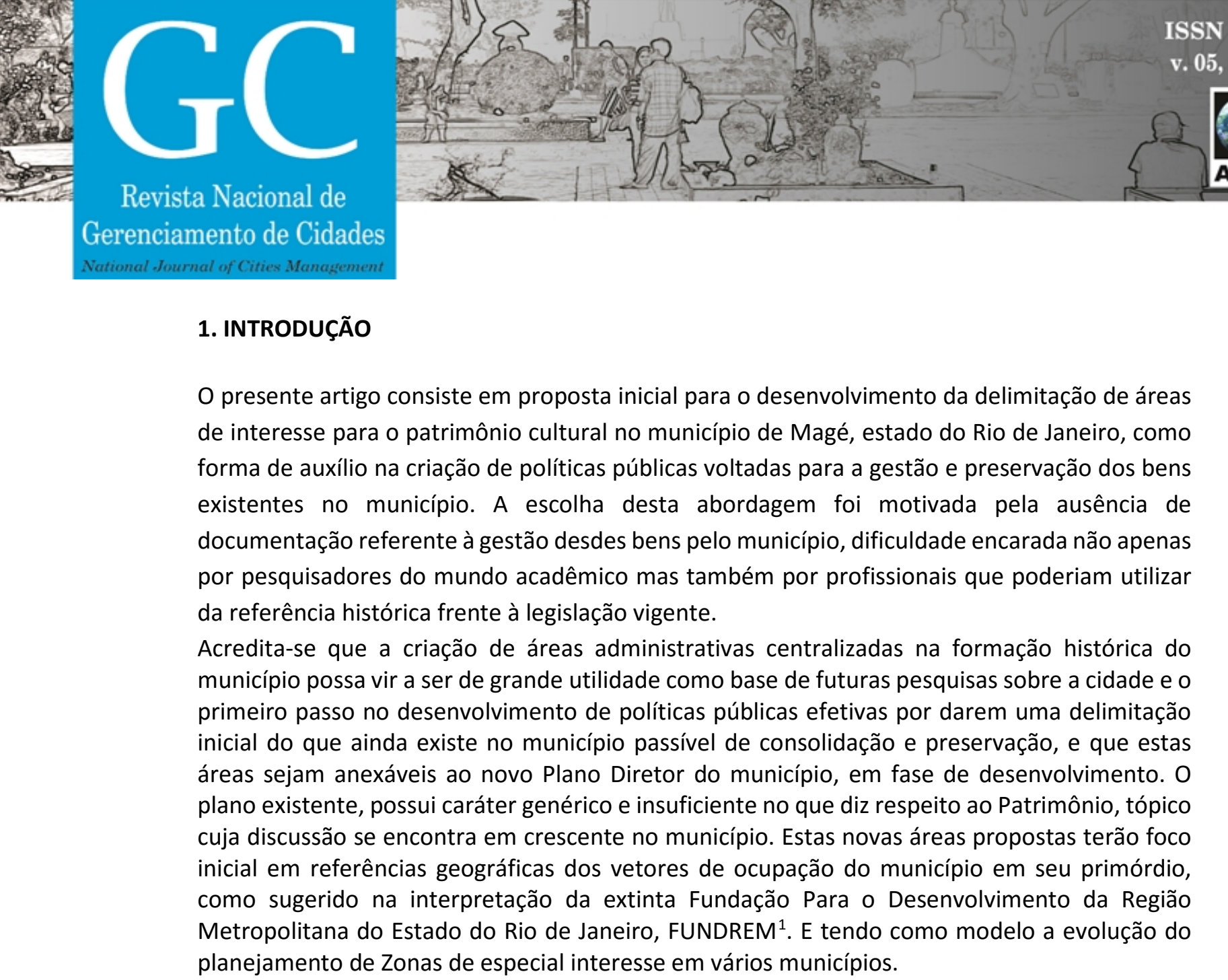

\section{INTRODUÇÃO}

O presente artigo consiste em proposta inicial para o desenvolvimento da delimitação de áreas de interesse para o patrimônio cultural no município de Magé, estado do Rio de Janeiro, como forma de auxílio na criação de políticas públicas voltadas para a gestão e preservação dos bens existentes no município. A escolha desta abordagem foi motivada pela ausência de documentação referente à gestão desdes bens pelo município, dificuldade encarada não apenas por pesquisadores do mundo acadêmico mas também por profissionais que poderiam utilizar da referência histórica frente à legislação vigente.

Acredita-se que a criação de áreas administrativas centralizadas na formação histórica do município possa vir a ser de grande utilidade como base de futuras pesquisas sobre a cidade e o primeiro passo no desenvolvimento de políticas públicas efetivas por darem uma delimitação inicial do que ainda existe no município passível de consolidação e preservação, e que estas áreas sejam anexáveis ao novo Plano Diretor do município, em fase de desenvolvimento. 0 plano existente, possui caráter genérico e insuficiente no que diz respeito ao Patrimônio, tópico cuja discussão se encontra em crescente no município. Estas novas áreas propostas terão foco inicial em referências geográficas dos vetores de ocupação do município em seu primórdio, planejamento de Zonas de especial interesse em vários municípios.

\section{HISTÓRICO E CONTEXTO}

O Município de Magé tem suas origens com o início da ocupação Portuguesa na orla da Baía de Guanabara, especialmente no século XVI, tendo sido um de seus primeiros acessos entre a Praia de Ipitinga e margens do Rio Suruí. Onde ainda hoje observa-se grande quantidade de manguezais e regiões alagáveis, outrora fora cenário de entrada para fazendas de engenhos de açúcar da Capitania do Rio de Janeiro, entrepostos comerciais dos produtos que vinham do interior e caminhos para as Minas Gerais durante o ciclo do ouro.

Esta longa faixa inundável recebeu os primeiros assentamentos da região, hoje município de Magé, com a construção de igrejas e capelas de localização estratégica sobre a baía da Guanabara por volta de 1650, bem como a área elevada da Piedade. Gerando assim três das principais Freguesias originais da região: Freguesia de Nossa Senhora da Guia de Pacobaíba, Freguesia de São Nicolau de Suruí e Freguesia de Nossa Senhora da Piedade de Magepe. Cujo território era ocupado principalmente pelo cultivo da cana de açúcar e mandioca.

Outro importante destaque histórico no município, se deu por volta do século XVIII, quando seus portos escoavam grande parte da produção cafeeira da região ${ }^{2}$, no século $\mathrm{XIX}$, com a

\footnotetext{
${ }^{1}$ FUNDAÇÃO PARA O DESENVOLVIMENTO DA REGIÃO METROPOLITANA DO RIO DE JANEIRO, Rio de Janeiro. Evolução urbana da região metropolitana do Rio de Janeiro. Rio de Janeiro, 1978.

${ }^{2}$ Vale do Café: Vassouras, Resende, Piraí, dentre outros.
} 
transferência da fábrica de pólvora do Rio de Janeiro para a região do Porto Estrela (1831) e com a inauguração da Estrada de Ferro Mauá $(1854)^{3}$. No fim do século XIX, a criação de nova rota para o município de Petrópolis, através da Estrada de Ferro D. Pedro II, e a crise da produção cafeeira, a região sofre impacto direto, entrando num período de decadência por falta de mão de obra para produção, escoamento e manutenção de suas principais áreas.

Após este período, a região de Magé, com suas estruturas de estrada de ferro, atrativos de clima úmido e condições geográficas favoráveis, atrai para si os novos modelos de indústria oriundos da revolução industrial, importadas pelo capitalismo internacional ${ }^{4}$. Bem como a implantação da estrada de ferro para a Central do Brasil, cria um novo processo de crescimento urbano da cidade, buscando agora a estrada de ferro ao invés dos portos (figuras 01, 02 e 03).

Figura 01 - Mapa do Município de Magé no século XVIII.

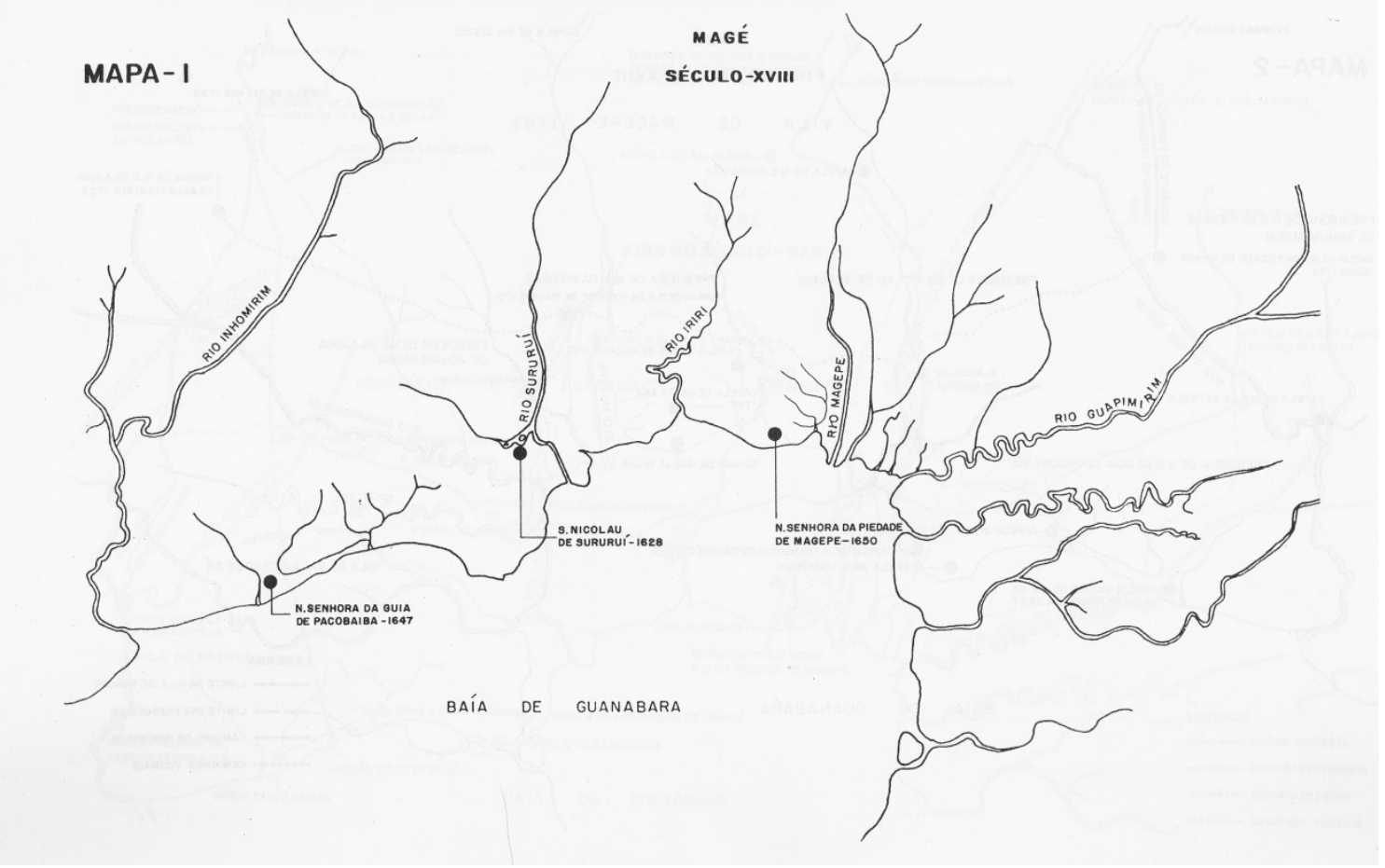

Fonte: FUNDREM, 1984.

\footnotetext{
${ }^{3}$ Instalada por Irineu Evangelista de Souaa, o Barão de Mauá, foi a primeira estrada de ferro do país. Funcionava como transporte modal entre a orla de Mauá e a Raiz da Serra.

${ }^{4}$ Modelos fabris ingleses são implantados nas regiões de vale e subida das serrras da região, como Santo Aleixo e Pau Grande. Seguindo diretrizes paternalistas e, por vezes, autoritárias, vemos crescer pequenos centros urbanos entre os anos de 1870 e 1900, afastados ou isolados dos antigos centros e compostos de vilas operárias, escola, igreja, armazéns, banda de música e edifícios de produção. Em inícios do século XX, com a modernização da produção e as guerras na europa, a produção destas regiões se vê em números crescentes, tendo decaído apenas após os anos 70.
} 
Revista Nacional de

Gerenciamento de Cidades

Figura 02 - Evolução do Mapa do Município de Magé nos fins do século XVIII.

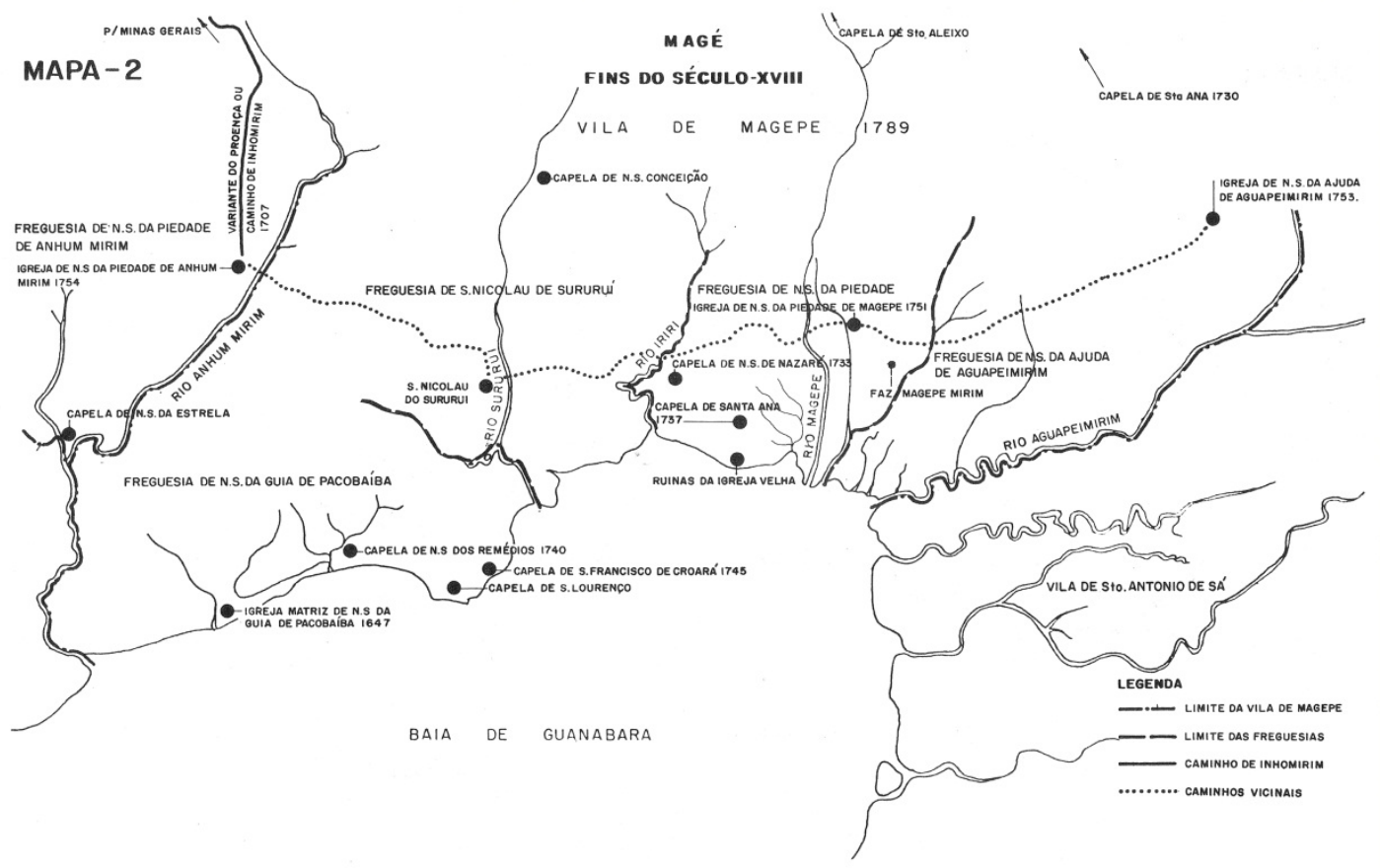

Fonte: FUNDREM, 1984.

Figura 03 - Evolução do Município de Magé nos fins do século XIX.

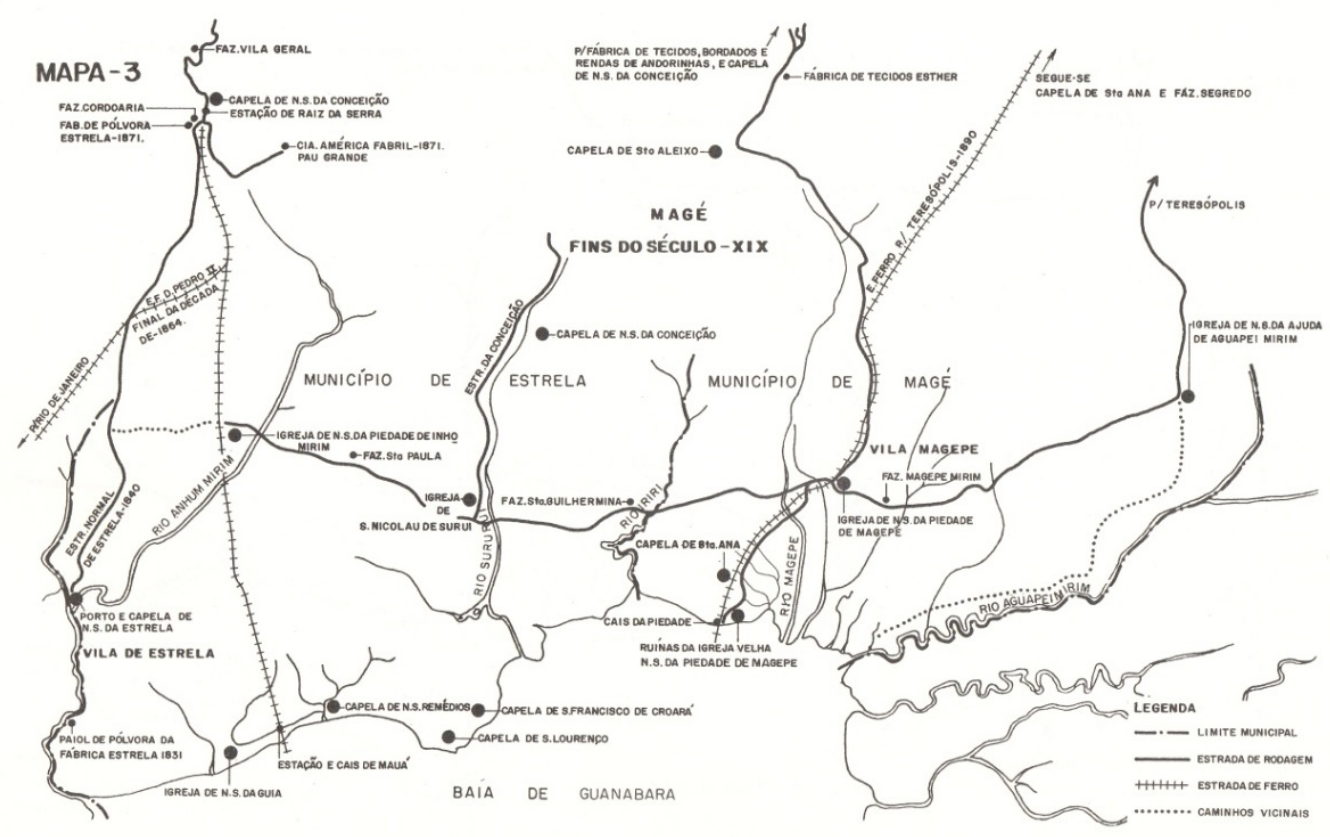

Fonte: FUNDREM, 1984.

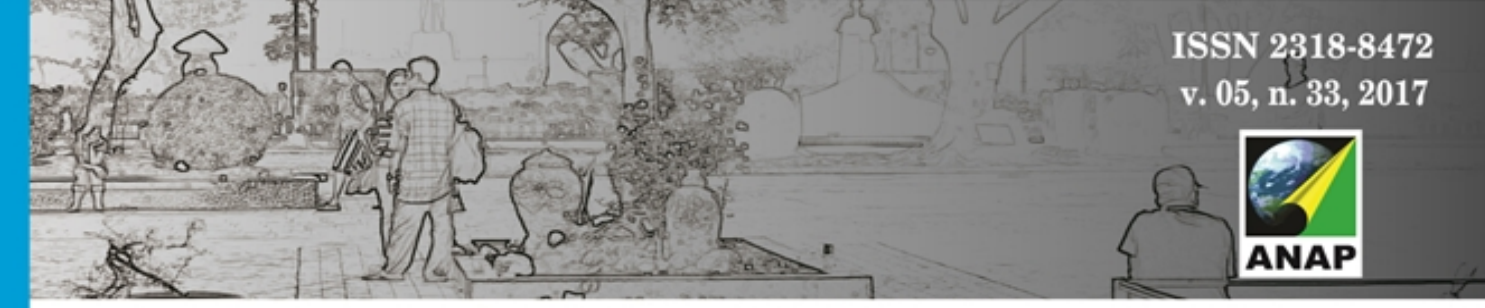




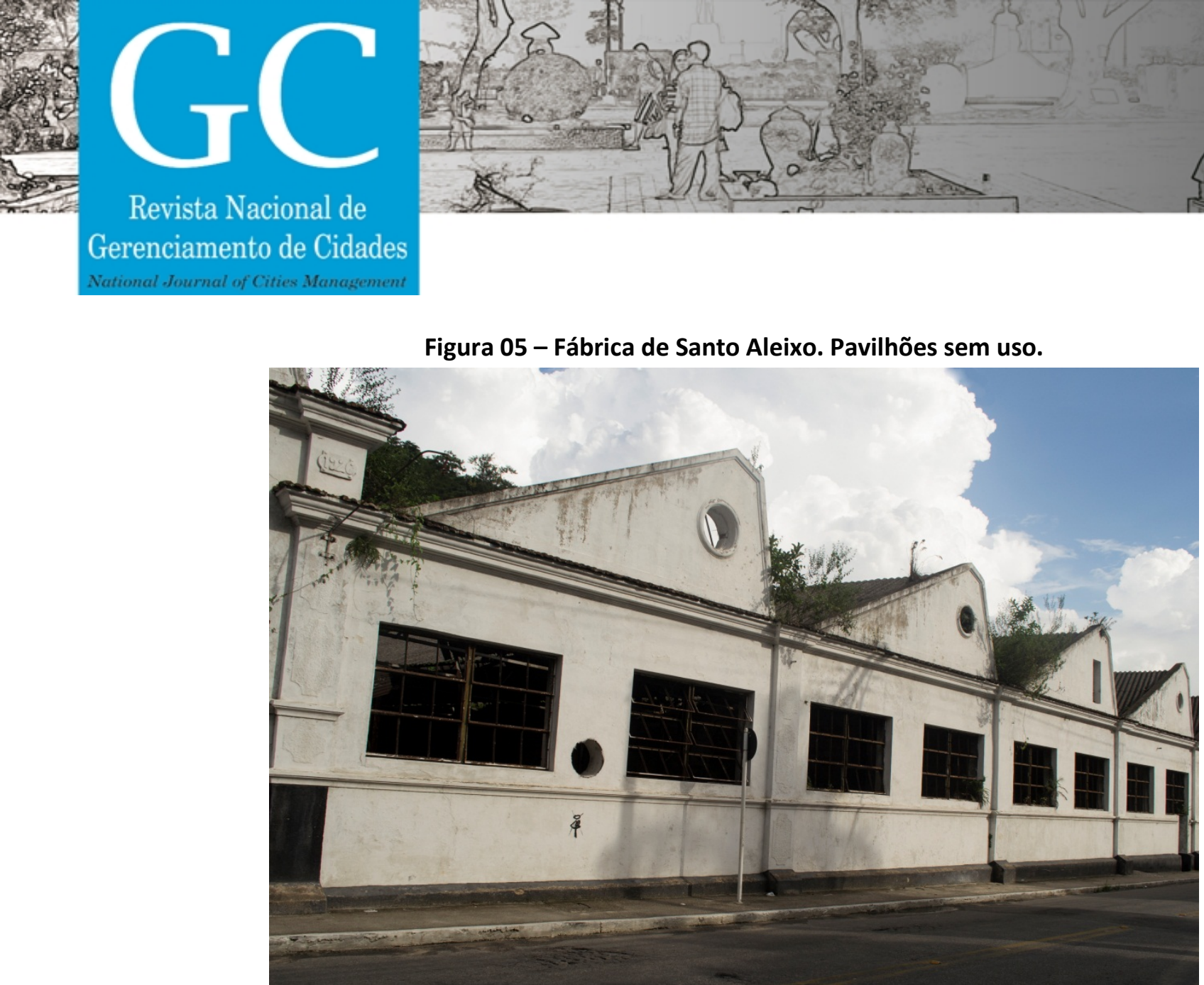

Fonte: Fotografia da Autora, 2015.

Em outubro do ano de 2013, a prefeitura de Magé cria o Conselho Municipal de Política Cultural do município, subordinado à Secretaria de Educação e Cultura que, dentre leis de incentivo e fomento à cultura, previa a criação de uma Lei de Tombamento e Preservação do Patrimônio Cultural de Magé. Até o presente momento, apesar da existência do tombamento de diversos bens no município, não é amplamente divulgada discussão ou critérios reais dos valores considerados para os tombamentos, ou como eles estarão inseridos no planejamento urbano da cidade.

Sabe-se, no entando, que dentre os bens tombados se encontram exemplares de Igrejas da era Colonial, como a Igreja Matriz de Nossa Senhora da Piedade de Magé, Igreja de Nossa Senhora da Piedade de Inhomirim, Igreja de Nossa Senhora da Guia de Pacobaíba, Igreja de São Nicolau de Suruí, Capela de Nossa Senhoa dos Remédios, Capela de São Francisco do Croará, Capela de Nossa Senhora da Conceição de Suruí, Capela de Nosso Senhor do Bonfim, Capela de Santo Aleixo, e também a Casa sede da Fazenda Magepe-mirim, dentre outros. Mas, encontram-se também, no Boletim Informativo Oficial de número 525, o tombamento de jazigo no cemitério principal da cidade:

Considerando os relatos populares que no jazigo 6003 do Cemitério Nossa Senhora de Piedade I - Magé I, situado à Rua Coronel Macieira, $\mathrm{s} / \mathrm{n}$ - - Magé se encontra sepulto há mais de século um padre que serviu a este Município, permanecendo como local de visitação e conservação por diversas pessoas face a seu valor histórico; (Boletim Informativo Oficial da Prefeitura de Magé, no525) 





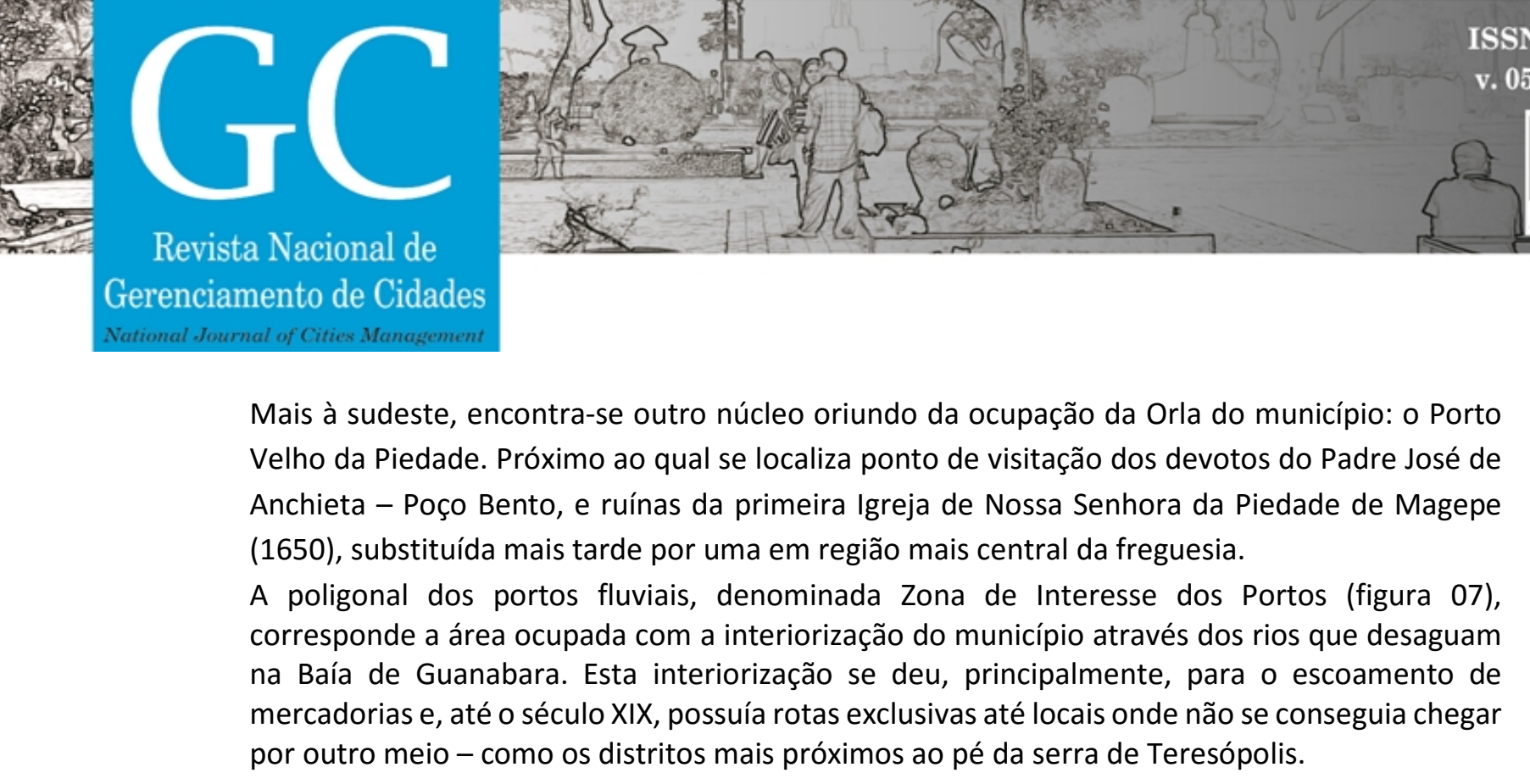

\section{Figura 07 - Município de Magé com delimitação de sua área e APAC dos Portos em cor diferenciada}

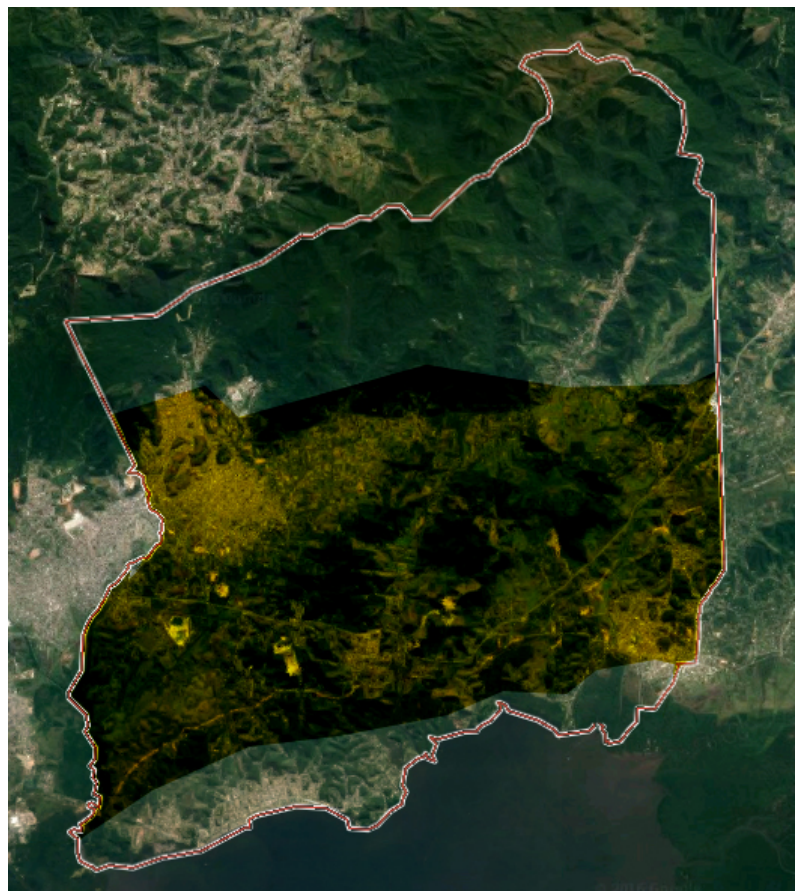

Fonte: Edição da autora sobre imagem do Google Earth, 2016.

Nesta área, apenas o núcleo de Suruí mantém a relação com seu Porto, ainda o mantendo como meio de transporte e utilidade. Os pescadores ainda possuem forte influência nesta região, cuja morfologia e traçados originais têm se mantido, especialmente, em comparação ao restante do município. Outro núcleo desta definição, hoje o primeiro distrito de Magé, devido à forças relacionadas ao crescimento urbano e administrativo da cidade, viu sua estrutura e relação com o Porto abandonadas. Bem como os demais portos: Ajuda, Estrela e Inhoirim, onde em alguns casos só permanecem ruínas dos edifícios religiosos, já em vias de desaparecimento.

A fábrica de Pólvora implantada no município se encontra nesta poligonal, bem como uma rede de fazendas e núcleos de produção rural, formadoras dos caminhos e estradas destinadas à interiorização e escoamento de mercadorias. 


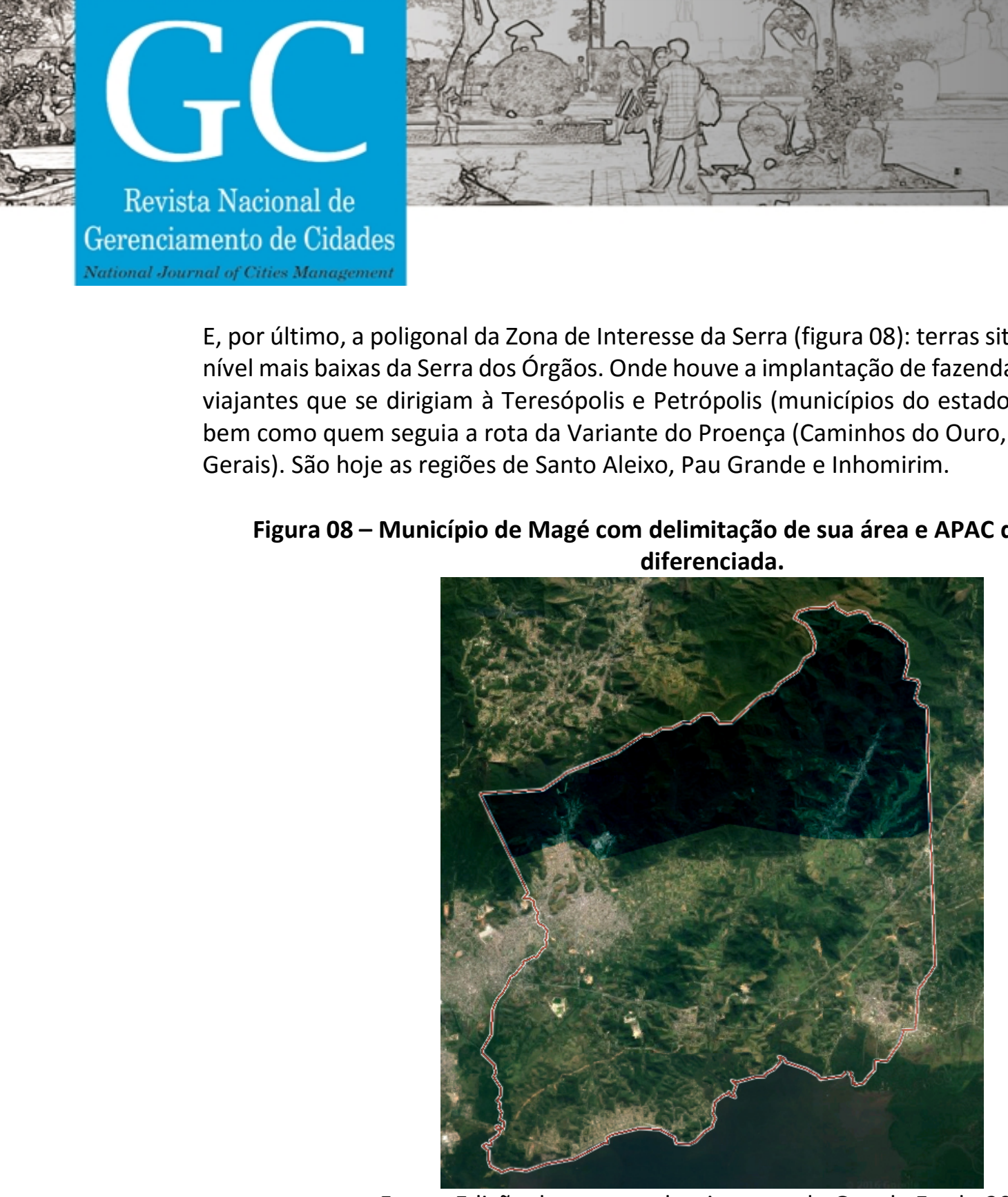

E, por último, a poligonal da Zona de Interesse da Serra (figura 08): terras situadas nas curvas de nível mais baixas da Serra dos Órgãos. Onde houve a implantação de fazendas, para repouso dos viajantes que se dirigiam à Teresópolis e Petrópolis (municípios do estado do Rio de Janeiro), bem como quem seguia a rota da Variante do Proença (Caminhos do Ouro, em direção à Minas Gerais). São hoje as regiões de Santo Aleixo, Pau Grande e Inhomirim.

\section{Figura 08 - Município de Magé com delimitação de sua área e APAC da Serra em cor}

Fonte: Edição da autora sobre imagem do Google Earth, 2016.

Nestas regiões, observa-se remanescentes peculiares de sua ocupação. Como pequeno arruamento na região de Inhomirim, subida do Caminho do Proença, e o porão da antiga Fazenda da Mandioca ${ }^{9}$, cuja construção de fato, foi descaracterizada e ocupada irregularmente. E Fábrica Estrela, cuja edificação em estilo neoclássico, em estado regular de preservação, se mantém imponente.

Pau Grande e Santo Aleixo abrigavam a arquitetura industrial da região. Embora as fábricas de Pau Grande tenham sido demolidas quase em sua totalidade, as de Santo Aleixo até hoje se mantêm, em variados estados de conservação. A ocupação desta região, se deu não só pela abundancia em recursos naturais, principalmente a água, mas graças ao clima úmido e às temperaturas amenas.

\section{CONSIDERAÇÕES FINAIS}

\footnotetext{
${ }^{9}$ Fazenda do Coronel João Antônio, onde encontrava-se o rancho onde o viajante naturalista e consul da Rússia no Brasil, von Langsdorff, fez estadia.
} 


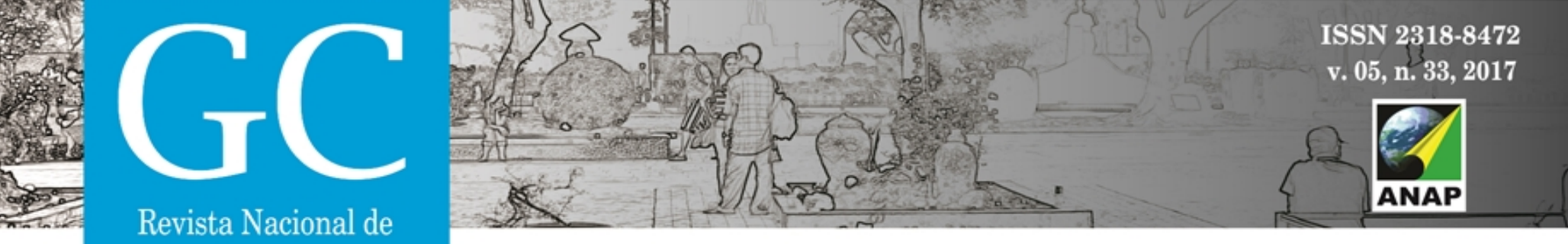
Gerenciamento de Cidades

National Journal of Cities Manasemen

GALLO, Haroldo. São Paulo - Três experiências de intervenção e restauração e um paradoxo. La Cultura Arquitectonica hacia 1900: Revalorización Critica y Preservación Patrimonial. Buenos Aires, 1999.

KÜHL, Beatriz Mugayar. Preservação do Patrimônio Arquitetônico da Industrialização: Problemas teóricos de Restauro. Cotia - SP: Ateliê Editorial, 2008.

RIEGL, Alois. El Culto Moderno a los monumentos. Madri: Visor Dis, S.A., 1999.

SANTOS, Renato Peixoto. Magé - Terra do "Dedo de Deus". Rio de Janeiro: IBGE, 1957. 